\title{
E-cigarette ban proposed in Toronto
}

A

proposed ban on the use of e-cigarettes in public spaces throughout the City of Toronto could be a bold first step in capping the widespread use of the unregulated products - as well as highlighting the lack of action by the provincial and federal governments.

The city's Medical Officer of Health Dr. David McKeown issued a report Aug. 1 calling for a city-wide ban on the use of e-cigarettes in public places similar to the one in place for cigarettes. The report will be considered by the Board of Health Aug. 18.

The Toronto Public Health report states that e-cigarettes are a public health concern because of emerging evidence of health and safety risks, lack of quality control, increased use by youth and their detrimental effect on efforts to denormalize smoking.

The report cites "regulatory gaps at the federal, provincial and municipal levels," and calls on the Ontario Minister of Health and Long-Term Care, Dr. Eric Hoskins, to make amendments to the 2006 Smoke-Free Ontario Act (SFOA). Those amendments include prohibiting open displays of e-cigarette products in retail stores and the sale of the devices to minors, as well as banning the use of e-cigarettes wherever smoking is currently prohibited in the province.

McKeown is also working with the city manager to potentially prohibit e-cigarette use at city workplaces, similar to restrictions in other jurisdictions in Canada, including Red Deer, Alberta and Hantsport, Nova Scotia.

Of particular concern is the use of e-cigarettes by minors, says Dr. Barbara Yaffe, associate medical officer of health at Toronto Public Health. "We know that right now, even in Toronto, e-cigarettes, including those with nicotine, are more and more available at retail outlets - there's no restriction on their purchase by minors. So we felt we needed to advocate for action before they become even a bigger problem."

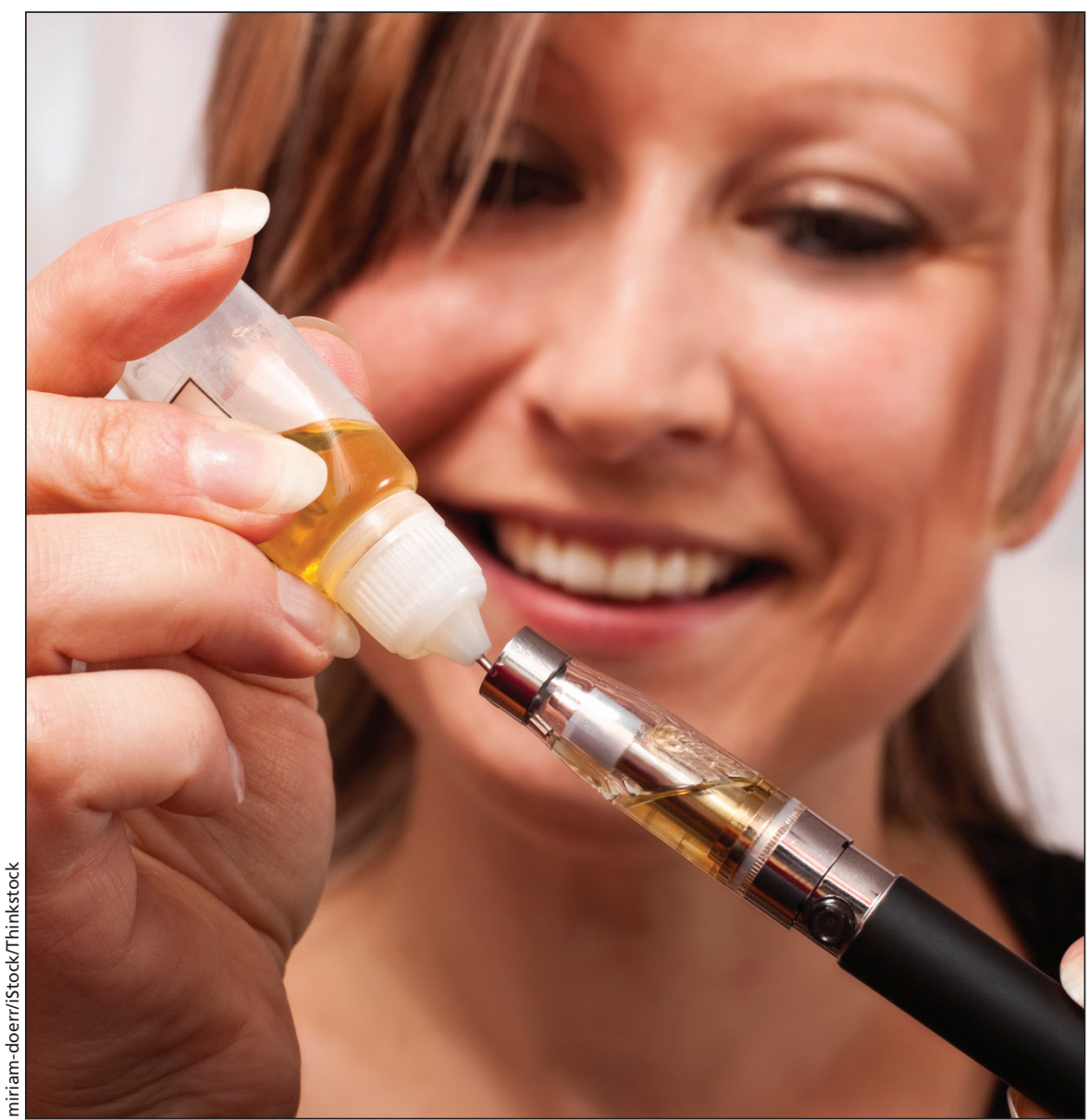

Nicotine for e-cigarettes is increasingly available at Toronto stores, despite a federal ban on the product.

In 2013 , about $15 \%$ of Ontario's youth in grades 9-12 (about 100000 students) had used e-cigarettes and nearly $5 \%$ had used nicotine-containing e-cigarettes, according to the report.

The public health report specifically targets "youth friendly e-cigarette flavours" and calls for the government to ensure consistency in labelling and manufacturing of e-cigarettes, which are currently not subject to the packaging, labelling, advertising, promotion and sponsorship restrictions that apply to traditional cigarettes.

Health Canada commissioned a study earlier this year tracking the sale of the products, but Yaffe says more needs to be done. "Under the Food and Drug Act, e-cigarettes that include nicotine or that have some health claim are not supposed to be imported or advertised or sold but their enforcement of this is quite weak."

"I think that we need to have the same kind of regulation of e-cigarettes as we have as regular cigarettes," says Yaffe. "That's not to say that people wouldn't be allowed to use e-cigarettes, just regulating their sale and distribution and where they can be smoked."

The Ontario Ministry of Health and Long-Term Care is monitoring the issue and emerging research. But according to a ministry spokesperson, Samantha Grant, "The federal government should take a more active role in 
regulating e-cigarettes and enforcing the existing federal prohibition related to e-cigarettes. Furthermore, the federal government should conduct research to define e-cigarettes as a drug or a tobacco product and to articulate its role and usefulness as a cessation aid."
Sean Upton, spokesperson for Health Canada, stated in an email that its position on the products has not changed, and that e-cigarettes that deliver nicotine are considered drugs under the Food and Drugs Act. Companies wishing to sell them must submit scientific evidence to Health Canada showing safety, quality and efficacy. To date, none of these products has been granted marketing authorization, stated Upton. - Adam Miller, Toronto, Ont.

CMAJ 2014. DOI:10.1503/cmaj.109-4873 